\title{
Kwetsbare wijken in Noord-Brabant op de kaart voor dialoog over maatschappelijke ondersteuning
}

\author{
Antje Eugster · Wendy Jeeninga · Arthur Rijkers · Ruben Smeets · Ike Kroesbergen · Mariëlle Cloïn
}

Published online: 28 January 2019

(C) The Author(s) 2019

Samenvatting Kwetsbare mensen vormen een belangrijke doelgroep van maatschappelijke ondersteuning. Ook de Provincie Noord-Brabant zet zich in voor kwetsbare groepen, zodat zij aansluiting hebben en houden in onze maatschappij. Het programma Sociale Veerkracht moet ervoor zorgen dat meer mensen kunnen delen in en bijdragen aan een goede kwaliteit van leven in Brabant. In opdracht van de provincie hebben verschillende partners in Noord-Brabant een verdieping aangebracht op de monitor sociale veerkracht, waarbij extra accent op gezondheid en de focus op kwetsbaarheid en kwetsbare mensen is gelegd. De gegevens zijn bovendien in de monitor op het lagere schaalniveau van de wijk gepresenteerd. Dit artikel beschrijft hoe het proces binnen het project Kwetsbaar Brabant. Een verdieping op de monitor Sociale Veerkracht is verlopen en welke opbrengsten het heeft opgeleverd.

\section{A. Eugster $(\bowtie)$}

GGD Brabant-Zuidoost/Academische Werkplaats Publieke Gezondheid Brabant, Tranzo, Tilburg University, Tilburg, Nederland

a.eugster@ggdbzo.nl

\section{$\mathrm{W}$. Jeeninga}

GGD Hart voor Brabant/Academische Werkplaats Publieke Gezondheid Brabant, Tranzo, Tilburg University, Tilburg, Nederland

A. Rijkers · I. Kroesbergen

GGD West-Brabant, Tilburg, Nederland

\section{R. Smeets}

Telos, Tilburg University, Tilburg, Nederland

\section{Cloïn}

Academische Werkplaats Publieke Gezondheid Brabant, Tranzo, Tilburg University, Tilburg, Nederland
Trefwoorden Kwetsbaar Brabant - kwetsbaarheid . wijkniveau $\cdot$ sociale veerkracht

Visualizing vulnerable districts in Noord-Brabant with the aim of a dialogue about social support

Abstract Vulnerable people are an important target group for social support. The Province of NoordBrabant is also committed to support vulnerable groups, in order to achieve that they remain socially connected. The program 'Sociale Veerkracht' (social resilience) has to ensure that more people share in and contribute to a good quality of life in Brabant. Commissioned by the Province, the monitor 'Sociale Veerkracht' has been further elaborated in cooperation with various partners. Thereby, health and the focus on vulnerability and vulnerable people were

\section{Kernpunten}

- In opdracht van de provincie Noord-Brabant hebben verschillende partners (GGD'en, Het PON, Telos, Tranzo/Universiteit van Tilburg) een verdieping aangebracht op de monitor Sociale Veerkracht.

- Hierbij is het perspectief van gezondheid en kwetsbaarheid van de mensen in de wijk nadrukkelijker meegenomen.

- De verdieping geeft meer inzicht door het lagere schaalniveau van de wijk.

- Indicatoren van (aspecten van) kwetsbaarheid zijn op wijkniveau vertaald naar geografische kaarten.

- Deze kaarten kunnen dienen als signaleringsinstrument en gesprekshulpmiddel voor gemeenten en professionals om samen met anderen aan oplossingen te werken. 
emphasized. It was also the desire to include data of a lower scale of the district. The current article describes the process and results of the project Kwetsbaar Brabant. Een verdieping op de monitor Sociale Veerkracht.

Keywords 'Kwetsbaar Brabant' · vulnerability · district level · 'sociale veerkracht'

\section{Inleiding}

Binnen de politiek en het beleid is kwetsbaarheid een belangrijk onderwerp. Kwetsbaarheid belemmert mensen om optimaal deel te nemen aan de samenleving. Maatschappelijke uitval ligt op de loer, vooral als de problemen zich opstapelen of escaleren. Hoe en waar die kwetsbaarheid zich uit, kan echter van persoon tot persoon verschillen. Maatschappelijke participatie (ofwel 'meedoen') is een doel van de Wet maatschappelijke ondersteuning (Wmo). Zowel op centraal als decentraal niveau is de overheid verantwoordelijk voor het bevorderen van de zelfredzaamheid en participatie van mensen. Ook de Provincie Noord-Brabant zet zich in om kwetsbare groepen te ondersteunen, zodat zij aansluiting hebben en houden in onze maatschappij. Het programma Sociale Veerkracht moet ervoor zorgen dat meer mensen kunnen delen in en bijdragen aan een goede kwaliteit van leven in Brabant.

Bij de Provincie Noord-Brabant bestond de wens om het thema 'gezondheid' meer te integreren in de vraagstukken rondom kwetsbaarheid en sociale veerkracht. Concreet was de vraag hoe het concept sociale veerkracht en de manier waarop dit tot nu gemeten is, te versterken is door het perspectief van gezondheid en kwetsbaarheid nadrukkelijker mee te nemen. Het doel was tweeledig: 1) de lacune in de monitor Sociale Veerkracht op het terrein van individuele hulpbronnen (gezondheid/kwetsbaarheid) invullen en hiermee de monitor verbeteren; 2) een monitor ontwikkelen om de dialoog aan te gaan en handelingsperspectief te ontwikkelen, om met en voor kwetsbare mensen de situatie te verbeteren. Aangezien de GGD'en de publieke gezondheid van burgers monitoren, hebben de drie Brabantse GGD'en (Brabant-Zuidoost, Hart voor Brabant en West-Brabant) met het RIVM en Tranzo/ Tilburg University (verenigd in de Academische Werkplaats Publieke Gezondheid Brabant), samen met Telos en het kennisinstituut Het PON de vragen van de Provincie opgepakt. In dit artikel wordt het proces beschreven waarbij kwetsbare wijken in Noord-Brabant in beeld zijn gebracht.

\section{Van data naar dialoog}

Een belangrijk onderdeel binnen het project, genaamd Kwetsbaar Brabant. Een verdieping op de monitor Sociale Veerkracht, was de samenwerking tussen de hierboven genoemde partners. Kennis vanuit professionals (beleid, onderzoek, praktijk) en de wetenschap is gecombineerd, waarbij alle partners hun expertise hebben gebundeld. De leden afkomstig van de drie Brabantse GGD'en, Tranzo, Telos en Het PON namen zitting in de project- en stuurgroep. De opdrachtgever was vertegenwoordigd in de stuurgroep. Gedurende de looptijd van het project zijn steeds gezamenlijke werksessies gehouden. Hieraan namen naast de leden van de stuurgroep en de projectgroep, ambtenaren van vier gemeenten verspreid over de provincie Noord-Brabant deel. Dit betrof de gemeenten Etten-Leur, Helmond, Oisterwijk en Waalwijk. Zo konden kennis en ervaringen uit de gemeentelijke praktijk voor het project worden gebruikt.

Van december 2016 tot en met september 2017 hebben de projectgroep, de stuurgroep en de participerende gemeenten in een gezamenlijk traject verschillende stappen gezet. De opbrengsten van de verschillende stappen zullen afzonderlijk worden toegelicht.

\section{Definitie van kwetsbaarheid}

In de eerste fase van het project zijn een definitie en een denkmodel ontwikkeld. Uit de voor dit project uitgevoerde literatuurverkenning over kwetsbaarheid is gebleken dat er in Nederland geen eenduidige definitie bestaat voor kwetsbaarheid of kwetsbare mensen. De definitie van kwetsbare mensen is afhankelijk van context en locatie, met steeds andere accenten en concepten [1]. Voorbeelden hiervan in de literatuur zijn definities van kwetsbare mensen bij rampen [2], kwetsbaren in de maatschappelijke zorg [3], kwetsbare ouderen (frailty) [4] of kwetsbare kinderen [5].

Vervolgens is gezocht naar elementen die bruikbaar zijn voor een algemeen construct en een algemene definitie van kwetsbare mensen die voor verschillende leeftijdsgroepen en in verschillende situaties toegepast kunnen worden.

Op basis van de literatuurverkenning in combinatie met de input vanuit de project- en stuurgroep en de participerende gemeenten, is gekozen voor de volgende definitie van kwetsbaarheid: kwetsbare mensen bevinden zich in een toestand waardoor ze bij een bedreigende gebeurtenis een grote kans hebben op een negatieve uitkomst.

In het project Kwetsbaar Brabant lag de focus op mensen (volwassenen 19+) die als gevolg van meerdere, elkaar beïnvloedende risicofactoren maatschappelijk dreigen uit te vallen. Het gaat hierbij nadrukkelijk om de sociaaleconomische omstandigheden waarin mensen zich bevinden. Kwetsbaarheid wordt niet als statisch beschouwd, maar juist als iets waar mensen tijdelijk mee geconfronteerd worden. Het beeld dat geschetst wordt is evenwel dat van een 'foto': de stand van zaken op basis van een aantal indicatoren op dat moment in de tijd.

Ter illustratie: een persoon die moeite heeft om financieel rond te komen (toestand) en zijn baan verliest (bedreigende gebeurtenis) loopt risico op gro- 
tere financiële problemen (schuldenproblematiek) en mogelijk in samenhang hiermee psychische klachten (beide negatieve uitkomsten). Of dit baanverlies daadwerkelijk leidt tot deze negatieve uitkomsten, hangt af van beschermende factoren, zoals hulp in de omgeving of de strategieën die de persoon heeft om met financiële tekorten en de stress die daardoor ontstaat om te gaan (veerkracht).

In het project is niet de kwetsbaarheid van individuele mensen in beeld gebracht, maar het risico op kwetsbaarheid in wijken. Een hoog risico op kwetsbaarheid in een wijk geeft aan dat er in die wijk relatief veel mensen wonen die op een of meer risicofactoren hoog scoren.

\section{Conceptueel model}

Voor de indicatorenselectie in het project Kwetsbaar Brabant is een conceptueel werk- en denkmodel van kwetsbaarheid ontwikkeld. Uitgangspunt hierbij was de in dit project gehanteerde definitie voor kwetsbare mensen en de focus op de doelgroep die maatschappelijk dreigt uit te vallen. Wat vergroot de kans hierop? Wat zijn de factoren die van belang zijn om zeker mee te nemen als het om kwetsbaarheid gaat? In het werken denkmodel is gekozen voor zeven domeinen die (samen) van invloed zijn op kwetsbaarheid, te weten: inkomen, woonomgeving, lichamelijke gezondheid, psychische gezondheid, dagelijkse bezigheden, sociale samenhang en leefstijl. Deze keuze is mede gebaseerd op leefdomeinen die worden gehanteerd in de zelfredzaamheidsmatrix en de monitor sociaal kwetsbare groepen [6, 7].

De combinatie van de verschillende domeinen vormt de samenvattende maat voor kwetsbaarheid. Aan de hand van het denkmodel en de daartoe behorende domeinen heeft de selectie van indicatoren plaatsgevonden.

\section{Indicatorenset}

Bij het vaststellen van criteria voor de selectie van indicatoren was vooral het handelingsperspectief van groot belang. Daarom is bij de selectie een aantal criteria gehanteerd: a) de indicator is inhoudelijk een goede indicator voor sociaal kwetsbare groepen die maatschappelijk dreigen uit te vallen; b) de indicatoren zijn verspreid over verschillende leefdomeinen; c) de indicator biedt handelingsperspectief voor (gemeentelijk) beleid; d) er is sprake van een goede, duurzame beschikbaarheid van de gegevens van de indicator (toegankelijk, op wijkniveau beschikbaar en naar verwachting ook op de langere termijn periodiek beschikbaar); en e) de gegevens zijn van goede kwaliteit.

Vervolgens is er een groslist gemaakt aan indicatoren, verdeeld over de verschillende domeinen. Dit is gebeurd tijdens een gezamenlijke werksessie in subgroepen van professionals vanuit beleid, onderzoek en praktijk. Vervolgens zijn de resultaten van de subgroepen vergeleken en overeenkomsten en verschillen benoemd. Daarna heeft de projectgroep aan de hand van de criteria een voorstel gedaan voor de indicatorenset en deze besproken met de deelnemers van de werksessie. De gehele groep heeft nogmaals gewogen op de criteria, met als uitkomst de lijst zoals in tab. 1 is vermeld.

Om kwetsbaarheid in Brabant in kaart te brengen door middel van de vastgestelde indicatorenset is gebruikgemaakt van verschillende, reeds bestaande databronnen. De gebruikte bronnen bevatten gegevens op wijkniveau, met uitzondering van de gegevens uit Woononderzoek Nederland (WoON) en het Landelijk Alcohol en Drugs Informatie Systeem (LADIS). Deze gegevens zijn uitsluitend beschikbaar op gemeenteniveau.

\section{Data op wijkniveau}

\section{Gebiedsindeling}

Om uitspraken te kunnen doen op wijkniveau is de gebiedsindeling volgens de CBS-wijkniveaus gehanteerd. Deze is het meest universeel en voor het project Kwetsbaar Brabant het meest voor de hand liggend omdat verschillende databestanden gecombineerd worden. Daarnaast is deze indeling herkenbaar voor bestuurders, beleidsmakers en burgers. Volgens de CBS-wijkindeling (2015) gaat het in Noord-Brabant om 404 wijken (66 gemeenten).

\section{Normen}

Voor iedere indicator is een meetschaal of norm opgesteld. Door voor iedere wijk/gemeente met dezelfde meetlat te werken, is onderlinge vergelijking mogelijk. Omdat wettelijke, inhoudelijke of normatieve normen niet voorhanden waren, zijn voor Kwetsbaar Brabant vooral statistische normen gebruikt (landelijk of Brabants gemiddelde en spreiding).

\section{Domein- en totaalscore}

Voor het project zijn domeinscores en het totaalbeeld kwetsbaarheid berekend. Een domeinscore is een maat voor het risico op kwetsbaarheid in een wijk voor een specifiek domein. De indicatoren van het betreffende domein zijn geïndexeerd via de aan de indicatoren gestelde normen. Vervolgens zijn per domein de betreffende indexscores van de indicatoren opgeteld tot een domeinscore.

Een domeinscore bestaat uit een zestal categorieën, variërend van een laag tot een hoog risico op kwetsbaarheid. De indeling van deze categorieën heeft plaatsgevonden aan de hand van de normaalverdeling van de rangorde van de domeinscores.

$\mathrm{Er}$ is overwogen om een 'samengestelde score kwetsbaarheid' te berekenen op basis van de verschillende domeinscores. Hiervoor zouden de domeinscores gewogen kunnen worden ten opzichte van elkaar. Voor een dergelijke weging ontbreekt ech- 
Tabel 1 Indicatorenset van Kwetsbaar Brabant. Een verdieping op de monitor Sociale Veerkracht

\begin{tabular}{|c|c|c|}
\hline indicator & definitie & bron \\
\hline \multicolumn{3}{|l|}{ indicatoren inkomen } \\
\hline schulden & aandeel particuliere huishoudens dat een negatief vermogen bezit & CBS, $2013^{\mathrm{a}}$ \\
\hline bijstand & aandeel personen dat een bijstandsuitkering ontvangt & CBS, $2015^{\mathrm{a}}$ \\
\hline moeite met rondkomen & aandeel personen dat moeite heeft met rondkomen (uitgesplitst naar type kostenpost) & GGD, $2016^{b}$ \\
\hline \multicolumn{3}{|l|}{ indicatoren woonomgeving } \\
\hline verhuisgeneigdheid & aandeel personen dat aangeeft binnen twee jaar te willen verhuizen & WoON, $2015^{\mathrm{C}}$ \\
\hline vandalisme & aandeel vernielingen, beschadiging en misdrijven tegen openbare orde en gezag & CBS, $2015^{d}$ \\
\hline \multicolumn{3}{|l|}{ indicatoren lichamelijke gezondheid } \\
\hline lichamelijke beperkingen & $\begin{array}{l}\text { aandeel personen dat minimaal } 6 \text { maanden ernstig beperkt is in activiteiten vanwege } \\
\text { gezondheidsproblemen }\end{array}$ & $\mathrm{GGD}, 2016^{\mathrm{b}}$ \\
\hline slecht ervaren gezondheid & aandeel personen dat eigen gezondheid als slecht ervaart & GGD, $2016^{b}$ \\
\hline chronisch zieken & $\begin{array}{l}\text { aandeel personen met minimaal } 1 \text { chronische aandoening in het afgelopen jaar waar- } \\
\text { voor onder behandeling van een arts }\end{array}$ & GGD, 2016 \\
\hline \multicolumn{3}{|l|}{ indicatoren psychische gezondheid } \\
\hline psychische problemen & aandeel personen dat psychisch ongezond is & GGD, $2016^{b}$ \\
\hline zelfmoordgedachten & $\begin{array}{l}\text { aandeel personen dat afgelopen jaar vaak heeft overwogen om een einde te maken aan } \\
\text { het leven }\end{array}$ & GGD, $2016^{b}$ \\
\hline weinig regie over het eigen leven & aandeel personen dat weinig regie heeft over het eigen leven & GGD, $2016^{b}$ \\
\hline \multicolumn{3}{|l|}{ indicatoren dagelijkse bezigheden } \\
\hline geen vrijwilligerswerk & aandeel personen dat geen vrijwilligerswerk doet & GGD, $2016^{b}$ \\
\hline geen betaalde baan & aandeel huishoudens dat arbeid niet als voornaamste inkomensbron heeft & $\mathrm{CBS}, 2013^{\mathrm{a}}$ \\
\hline geen lid zijn van een vereniging & aandeel personen dat geen lid is van een vereniging & GGD, $2016^{b}$ \\
\hline \multicolumn{3}{|l|}{ indicatoren sociale samenhang } \\
\hline ernstige eenzaamheid & aandeel personen dat ernstig eenzaam is & GGD, $2016^{b}$ \\
\hline gebrek aan steun uit de omgeving & $\begin{array}{l}\text { aandeel personen dat niemand in de omgeving heeft die hulp kan bieden als daar } \\
\text { behoefte aan is vanwege de gezondheid }\end{array}$ & GGD, 2016 ${ }^{b}$ \\
\hline $\begin{array}{l}\text { ontevredenheid over betrokkenheid van } \\
\text { de buurt }\end{array}$ & $\begin{array}{l}\text { aandeel personen dat ontevreden is over de betrokkenheid van de buurt (sociale cohe- } \\
\text { sie) }\end{array}$ & GGD, $2016^{b}$ \\
\hline echtscheidingen & aandeel huwelijken dat door een echtscheiding is ontbonden & CBS, $2016^{d}$ \\
\hline \multicolumn{3}{|l|}{ indicatoren leefstijl } \\
\hline hulpvragers verslavingszorg & $\begin{array}{l}\text { aandeel personen dat in behandeling is bij de verslavingszorg voor drugs, alcohol, } \\
\text { gokken, enzovoort }\end{array}$ & LADIS, $2015^{\mathrm{e}}$ \\
\hline zwaar alcoholgebruik & aandeel personen dat overmatig drinker is & GGD, $2016^{b}$ \\
\hline ernstig overgewicht & aandeel personen met ernstig overgewicht & GGD, $2016^{b}$ \\
\hline \multicolumn{3}{|c|}{$\begin{array}{l}\text { a Centraal Bureau voor de Statistiek (CBS). CBS Microdata 2013, 2015. Beschikbaar via https://www.cbs.nl/nl-nl/onze- } \\
\text { microdata-zelf-onderzoek-doen } \\
\text { b GGD Brabant-Zuidoost, GGD Hart voor Brabant, GGD West-Brabant. Volwassenen- en Ouderenmonitor } 2016 \\
\text { c WoOn. Cijfers verhuisgeneigdheid. 2015. Beschikbaar via https://www.woononderzoek.nl/ } \\
\text { d Centraal Bureau voor de Statistiek (CBS). Gegevens 2013, 2015, 2016. Beschikbaar via https://www.cbs.nl/nl-nl/cijfers } \\
\text { e Ladis. Cijfers hulpvragers verslavingszorg. 2015. Beschikbaar via http://www.ladis.eu/nl/over-ladis/kerncijfers }\end{array}$} \\
\hline
\end{tabular}

ter de theoretische basis om een onderbouwde keuze te maken. Het is eerder aannemelijk dat het risico op kwetsbaarheid in een wijk groter is naarmate de wijk op meer domeinen 'kwetsbaar' scoort. Het 'totaalbeeld kwetsbaarheid' in een wijk is daarom bepaald aan de hand van het aantal domeinen waarop de betreffende wijk een hoog risico op kwetsbaarbaarheid heeft, waarbij alle domeinen even zwaar meewegen. Een wijk vormt een 'risicodomein' als deze op dat domein in een van de twee hoogst kwetsbare categorieën scoort: kwetsbaar of zeer kwetsbaar ( 1 of 2 standaarddeviaties vanaf het gemiddelde). Naarmate er voor een wijk meer (zeer) kwetsbare domeinen naar voren komen, neemt het risico op kwetsbaarheid voor die wijk toe: de totaalscore voor kwetsbaarheid bestaat zodoende uit acht categorieën, variërend van geen risicodomeinen tot en met zeven risicodomeinen.

\section{Minimum aantal respondenten per wijk}

Vanuit het oogpunt van privacy en betrouwbaarheid moet een wijk een minimum aantal respondenten bevatten. Wanneer dit niet het geval is, dan worden voor de betreffende wijk geen resultaten gepresenteerd en blijft deze 'blanco' op de kaart. Voor Kwetsbaar Brabant zijn hiervoor de volgende aantallen gehanteerd: $n=50$ voor de GGD Gezondheidsmonitor, $n=100$ voor het CBS. Dit laatste is conform de criteria van het CBS. Op basis van deze criteria zijn voor Kwetsbaar Brabant in totaal 376 wijken in kaart gebracht. 
Figuur 1 Provinciale kaart met de score op het domein psychische gezondheid in Noord-Brabant

Figuur 2 Provinciale kaart met het totaalbeeld Kwetsbaarheid in Noord-Brabant
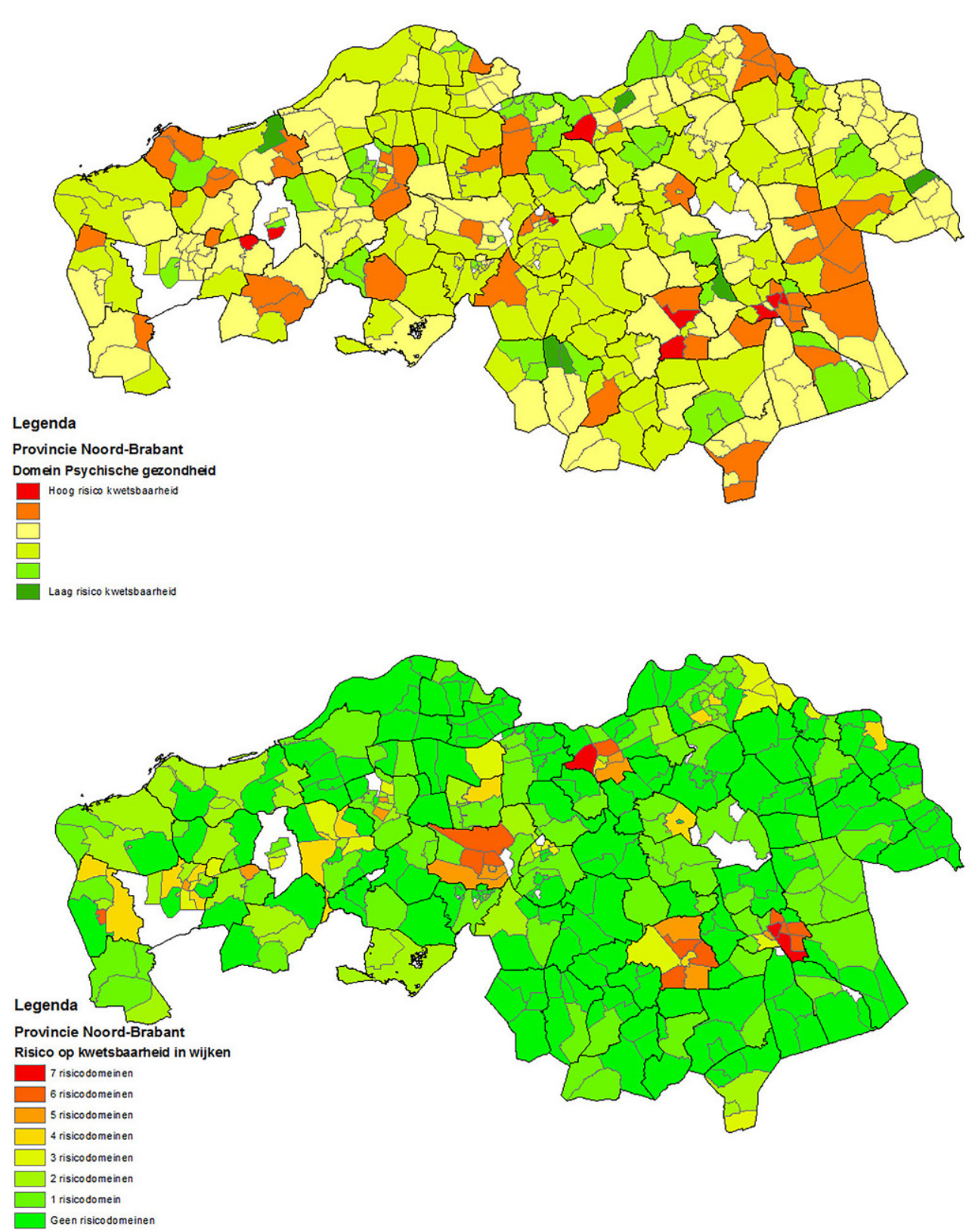

\section{Geografische presentatie}

Kwetsbaar Brabant heeft twee producten opgeleverd, namelijk een website met geografische kaarten en een rapportage.

\section{Website}

Voor de visualisatie van de resultaten van Kwetsbaar Brabant is gebruikgemaakt van geografische kaarten. De website www.kwetsbaarbrabant.nl, inmiddels geïntegreerd in www.Brabantscan.nl, bevat zeven provinciale kaarten van de afzonderlijke domeinen op wijkniveau en een provinciale kaart met het totaalbeeld kwetsbaarheid op wijkniveau. Daarnaast zijn voor alle 66 gemeenten in Noord-Brabant kaarten per gemeente op wijkniveau beschikbaar: zeven gemeentekaarten van het risico op kwetsbaarheid op de afzonderlijke domeinen en één gemeentekaart van het totaalbeeld kwetsbaarheid.

In fig. 1 staat een voorbeeld van een provinciale kaart op het domein psychische gezondheid. Uit de figuur blijkt dat in Noord-Brabant tien wijken op dit domein een hoog risico op kwetsbaarheid hebben (rode kleur). In fig. 2 is het totaalbeeld van kwetsbaarheid in de provinciale kaart weergegeven (op hoeveel domeinen een wijk kwetsbaar is). Ruim de helft van de wijken in Noord-Brabant is op geen enkel domein kwetsbaar. Vijftien wijken zijn kwetsbaar op ten minste zes domeinen.

De kaarten zijn vooral bedoeld als signaleringsinstrument. Door voor de hele provincie (aspecten van) kwetsbaarheid langs dezelfde meetlat te leggen zijn 
vragen te beantwoorden als: 'Waar zit de grootste kwetsbaarheid in Noord-Brabant?', 'Welke wijken in mijn gemeente zijn het meest kwetsbaar?' en 'Wat maakt dat deze wijk kwetsbaar is?' Ze nodigen uit tot een verdere verdieping en debat over werkingsmechanisme en handelingsperspectief.

\section{Rapportage}

Er is een verdiepend rapport geschreven, met een beschrijving van het proces van het project en een beschouwing over de resultaten van het project. Dit rapport is onder andere terug te vinden op de Brabantscan en bij de AWPG Brabant.

\section{Kwetsbaar Brabant in relatie met andere moni- tors}

Om de resultaten van Kwetsbaar Brabant te kunnen staven, is gekeken in hoeverre deze overeenkomen met de resultaten van andere monitors op het gebied van uitsluiting, deprivatie en/of leefbaarheid. Uit de vergelijking blijkt dat de totaalscore Kwetsbaarheid een zwakke positieve correlatie $(0,36)$ heeft met de Stapelingsmonitor KING [8] en een matige negatieve correlatie $(-0,63)$ met de Leefbaarometer [9]. Dit stemt overeen met respectievelijk de hypothese dat meer gebruik van regelingen in het sociaal domein samengaat met een hogere kwetsbaarheid en de hypothese dat een betere leefbaarheid samengaat met lagere kwetsbaarheid. Tevens is er een sterke positieve correlatie met de Multiple Deprivation Index (MDI) $(0,79)$ van de Monitor Sociale Veerkracht (Het PON/Telos) gevonden [10]. Kwetsbaar Brabant vormt een verdieping op de monitor Sociale Veerkracht door aanvulling met indicatoren van persoonlijke hulpbronnen en gezondheid, en versterking op het lagere schaalniveau van de wijk. Zoals verwacht wordt inderdaad een positieve correlatie gevonden tussen beide schalen.

\section{Beschouwing en conclusie}

De vraag van de provincie Noord-Brabant was om gezondheid en kwetsbaarheid nadrukkelijker mee te nemen, om zodoende het concept sociale veerkracht en de manier waarop deze tot nu gemeten is te versterken. Dit heeft geleid tot het project Kwetsbaar Brabant. Een verdieping op de monitor Sociale Veerkracht. Het project heeft verschillende producten voortgebracht. Dit heeft voor de monitor sociale veerkracht een versterking opgeleverd op het gebied van lichamelijke en psychische gezondheid, kwetsbaarheid en (deels) op het lagere schaalniveau van de wijk. Tevens zijn kwetsbaarheid en de monitoring daarvan nu verbonden aan de oplossingsrichtingen via sociale veerkracht. De resultaten van Kwetsbaar Brabant worden bevestigd door een aantoonbare samenhang met de eerder genoemde monitors op het gebied van uitsluiting, deprivatie en/of leefbaarheid.
Door het toepassen van één model van kwetsbaarheid voor iedere gemeente/wijk kunnen gemeenten en wijken onderling vergeleken worden en is het mogelijk wijken aan te wijzen die het hoogste risico op kwetsbaarheid hebben. Vooral de afzonderlijke domeinscores bieden handvatten voor alle betrokkenen om in te zoomen op datgene wat een wijk kwetsbaar maakt.

Er zijn ook enkele kritische punten. Zo valt een kanttekening te plaatsen bij de gegevensverzameling omdat een groot deel van de gegevens afkomstig is van de GGD Gezondheidsmonitor, waarin kwetsbare mensen mogelijk ondervertegenwoordigd zijn. Dit komt doordat er een gebrek is aan andere beschikbare databronnen op wijkniveau, waarvan de data in heel Brabant op dezelfde manier gemeten zijn. Het is echter aannemelijk dat de ondervertegenwoordiging vooral de groep betreft die al maatschappelijk uitgevallen is. Het doel van dit project was de groep in beeld te brengen vóór de maatschappelijke uitval. Deze groep is waarschijnlijk wel vertegenwoordigd in de monitors.

Daarnaast kwamen de wijken in de GGD-monitors niet altijd overeen met de CBS-wijkindeling. Bij de monitors betrof het in een aantal gevallen grotere clusters. Voor de CBS-wijken die in de betreffende clusters vallen zijn de percentages van die clusters gehanteerd. Ook voor de indicatoren verhuisgeneigdheid (WoON) en hulpvragers verslavingszorg (LADIS) waren de gegevens niet op CBS-wijkniveau beschikbaar. Dit is ondervangen door voor iedere wijk het gemiddelde van de betreffende gemeente te hanteren. Dit kan in sommige wijken leiden tot een onderschatting en in andere wijken tot een overschatting van het cijfer op de betreffende indicator, waardoor verschillen tussen wijken 'uitmiddelen' en minder zichtbaar worden.

Het is belangrijk dat de geografische kaarten als signaleringsinstrument worden ingezet. Ze nodigen uit tot een verdere dialoog en verdieping met lokale partners en burgers. Vertegenwoordigers van de gemeenten gaven aan dat het waardevol is om praktijkkennis (op casusniveau) te combineren met statistische gegevens, om na te gaan in hoeverre beide beelden met elkaar overeenkomen. De kaarten zijn bedoeld als gesprekshulpmiddel om een handelingsperspectief te ontwikkelen dat moet voorkomen dat kwetsbare mensen uitvallen. De resultaten kunnen interessant zijn voor zowel onderzoekers, beleidsmakers, gemeenteambtenaren en professionals die werken met kwetsbare groepen, als betrokken burgers die graag willen weten hoe hun wijk ervoor staat. Het materiaal van Kwetsbaar Brabant biedt handvatten om in te zoomen op datgene wat een wijk kwetsbaar maakt en hier iets aan te doen! Zo heeft een van de gemeenten die betrokken was bij het project de resultaten gekoppeld aan aandacht voor psychische problematiek en daarbij initiatieven van actieve burgers betrokken.

Een belangrijke aanbeveling is om de gegevens die gebruikt zijn regelmatig te updaten. Een aantal ge- 
gevens die in het huidige project gebruikt zijn, is inmiddels gedateerd. Hierdoor worden de kaarten in de toekomst minder geschikt als signaleringsinstrument. De kaarten van Kwetsbaar Brabant zijn inmiddels opgenomen in de Brabantscan, waarvoor geldt dat deze up to date moet blijven. De intentie is om bij nieuwe cijfers ook de kaarten up to date te houden. Een verbeterpunt hierbij is om op zoek te gaan naar gegevens over wonen en verslaving op wijkniveau.

Het project Kwetsbaar Brabant. Een verdieping op de monitor Sociale Veerkracht sluit aan bij de ambities van de Provincie om kwetsbaarheid in beeld te brengen en vanuit sociale veerkracht bij te dragen aan handelingsperspectief om maatschappelijke uitval te voorkomen. Dit samenwerkingsproject heeft ook bijgedragen aan de ambities van de Provincie om aanwezige monitors, rapportages en ontwikkelde instrumenten optimaal te benutten, alsmede te voorzien in aangrijpingspunten voor beleid en het vastleggen van werkwijze en resultaten, zodat deze overdraagbaar zijn. Al deze resultaten zijn bereikt dankzij een actieve betrokkenheid en input van alle samenwerkingspartners.

De samenwerking is door de projectpartners als goed ervaren. Vanuit deze ervaring hebben zij de ambitie om de samenwerking in de toekomst voort te zetten.

Dankbetuiging Arjen van den Broek (gemeente Etten-Leur), Astrid van Oosterhout (gemeente Oisterwijk), Gooitske Marsman (gemeente Helmond), Wytske Teeuwen-Besseling (gemeente Helmond) en Iris Dijksterhuis (gemeente Waalwijk). Speciale dank aan Richard Dumont en Jolanda Schneider van de provincie Noord-Brabant voor het mogelijk maken van fase 1 van Kwetsbaar Brabant.

\section{Literatuur}

1. Winsemius A. Tussen draaglast en draagkracht. Kwetsbare groepen in gemeentelijkbeleid. Utrecht: Movisie; 2011.

2. IFRC. What is vulnerability? Beschikbaar via http://www. ifrc.org/en/what-we-do/disaster-management/aboutdisasters/what-is-a-disaster/what-is-vulnerability.

3. WolfJ. Niemand tussen wal en schip. Referentiekader maatschappelijke zorg voor mensen in multiprobleemsituaties. Nijmegen: Academische werkplaats OGGZ; 2015.

4. Campen C van. Kwetsbare ouderen. Den Haag: Sociaal en Cultureel Planbureau; 2011.

5. Romijn G, Graaf I de, Jonge M de. Kwetsbare kinderen. Literatuurstudie over verhoogde risicogroepen onder kinderen van ouders met psychische en verslavingsproblemen. Utrecht: Trimbos Instituut; 2010.

6. Lauriks S, Buster MCA, Wit MAS de, et al. ZelfredzaamheidMatrix. Amsterdam: GGD Amsterdam; 2013.

7. Brink C van den, Smulders G, Wolf J, Oers $H$ van, et al. Monitor Sociaal kwetsbare groepen, e-book. Tilburg: Tilburg University; 2015.

8. VNGRealisatie. Stapelingsmonitor. Beschikbaar via. https://www.vngrealisatie.nl/producten/stapelingsmoni tor.

9. Leidelmeijer K, Marlet G, Iersel J van, et al. De Leefbaarometer. Leefbaarheid in Nederlandse wijken en buurten gemeten en vergeleken. Amsterdam/Utrecht: RIGO/Atlas voor gemeenten, 2008. Beschikbaar via. https://www. leefbaarometer.nl/home.php.

10. Blanken M, Dagevos J, Smeets R, et al. Sociale veerkracht in Brabant. Tilburg: HetPON, Telos; 2016. 